Article

\title{
Biomass Equations for 24 Understory Species in Coniferous and Broadleaved Mixed Forests in Northeastern China
}

\author{
Huaijiang He ${ }^{1}$, Chunyu Zhang ${ }^{1, *}$, Fengguo Du ${ }^{2, *}$, Xiuhai Zhao ${ }^{1}$, Song Yang ${ }^{1}$ and \\ Qiang Zuo ${ }^{1}$ \\ 1 Key Laboratory for Forest Resources \& Ecosystem Processes, Beijing Forestry University, \\ Beijing 100083, China; 442488087.2007@163.com \\ 2 Forestry College, Beihua University, Jilin 130013, China \\ * Correspondence: zcy_0520@163.com (C.Z.); dfg4656@hotmall.com (F.D.); \\ Tel.: +86-10-6233-7605 (C.Z.); +86-432-6460-8330 (F.D.)
}

\begin{abstract}
Understory plants are important components of forest ecosystem productivity and diversity. Compared to biomass models of overstory canopy trees, few are available for understory saplings and shrubs and therefore their roles in estimation of forest carbon pools are often ignored. In this study, we harvested 24 understory species including 4 saplings, 9 tree-like shrubs and 11 typical shrubs in coniferous and broadleaved mixed forest in northeastern China and developed the best fit allometric equations of above- and below-ground and total biomass by species-specific or multispecies using morphological measurements of basal diameter, height and crown area as independent variables. The result showed that single basal diameter, height or crown area had good explanatory power for both species-specific and multispecies $(\mathrm{p}<0.001)$. The best-fit models included only basal diameter in sapling and tree-like shrubs, and combinations of crown area, height, and basal diameter in typical shrubs. The logarithmic model was most desired among the 4 model forms of linear, quadratic, multiple linear and logarithmic, for species-specific and multispecies. The models we developed should help the estimation of forest ecosystem carbon stocks, especially for belowground component, and provide tools for quantification of individual species biomass of understory plants.
\end{abstract}

Keywords: understory species; allometric biomass equation; species-specific and multispecies; temperate coniferous and broadleaved mixed forest; northeastern China

\section{Introduction}

Forests comprise the largest areas of terrestrial ecosystems and play an important role in maintaining an atmospheric $\mathrm{CO}_{2}$ balance [1]. Accurate estimation of biomass in forest ecosystems is useful for achieving sustainable forest management, assessing forest growth conditions, adjusting forest structures, estimating forest productivity, nutrient and energy flows as well as monitoring its carbon cycle [2-6]. Forests have gained wide attention in the past decades because of their enormous capacity for carbon storage in the global carbon pool [7-9]. Understory species in the forest, composed of saplings and shrubs, serve as important components of forest ecosystems [10], play important roles in forest structures and functions [11], maintain species diversity, promote forest regeneration and improve forest production [10,12-15]. Compared with the biomass of overstory trees species, the biomass of saplings and shrubs is often neglected because of a lack of measurement technique and the difficulty in 
their assessment [16].

Plant biomass can be determined through direct harvesting or estimated with allometric equations. Direct harvesting is more accurate, but is time-consuming and costly [16,17] and may not be practical or appropriate for understory plants. Comparatively, the use of allometric biomass is more practical and only requires the development of allometric biomass relationships of individual plants with their morphological variables, such as basal diameter, height or crown area [16,18-20]. A number of investigators have used allometric equations to develop species-specific or multispecies equations to measure biomass for forests [18,20-22], shrublands [17], alpine or subalpine ecosystems ${ }^{12,23}$ around the world. Currently, biomass equations for some shrub species have been developed for different ecosystems of the world $[19,23,24]$. However, biomass equations are scarce for understory species in closed forests [25], especially for temperate coniferous and broadleaved mixed forest ecosystem in northeastern China. We found that only a few species have been studied for biomass estimation [14,26,27]. Specially, there are several common shrub species in this ecosystem for which species-specific models have not yet been developed. As well, applicable multispecies models for this entire temperate forest area are lacking. Although Yang ea.al [26] and Li et.al [14] have developed several species-specific and multispecies biomass equations, these are not enough for a comprehensive estimation of forest biomass in this region of China .

Model formulations and the choice of predictor variables that vary by species or study areas are two of the most important factors that must be considered when developed the allometric biomass equations [28]. Different models and variable types have been used to predict shrub or tree species biomass [20,29]. Generally, power models, linear models (single and multiple) and logarithmic models have often been used to develop biomass equations $[14,17,24,29,30]$. Particularly power models, transformed into logarithmic models, may be one of the most commonly applied of all models as can be found in numerous studies in different ecosystem worldwide [17,25,31-34]. A single independent variable, such as basal diameter, height, crown area or a combination of two variables has turned out to be the best fit to develop biomass equations for shrubs or sapling species [16,17,24,26,35].

Belowground biomass plays a key role in supplying forest ecosystem services such as those related to primary production, carbon storage, soil conservation and nutrient cycling[36], but has received less attention compared to aboveground biomass[37]. This is due to the difficulty in sampling and estimating destructive and not-standardized methods, the high labor and time consumption and costs as well as considerable variation and uncertainty in root sampling, especially for small and fine roots. Belowground biomass accounts for about $20-30 \%$ in tree species [38] and may be more for shrub or sapling species. It is therefore important that belowground biomass should be estimated for these species. Currently, almost all studies about establishing biomass equations for shrub or sapling species concentrated only on aboveground biomass [17,24,33,34,39]. Belowground biomass equations are few and far between [16,27]. Hence, we explored belowground biomass for twenty four understory species in temperate forests and developed equations for these species.

In this study, our primary aim was (1) to develop species-specific equations of above-and below-ground biomass as well as total biomass for twenty four understory species in the coniferous and broadleaved mixed forest in northeastern China; (2) to develop multispecies equations according to the classification of saplings, tree-like shrubs and typical 
shrubs for these species and (3) to verify the prediction effectiveness of fitting the best fit model for multispecies. We wanted to provide a basic tool for accurately predicting understory species biomass and fill the information in the biomass study of understory species including tree saplings and shrubs. Also, we expect that more studies will be carried out for other species in other regions to supplement our pool of biomass models.

\section{Material and methods}

\subsection{Study area}

The study was carried out at the Jiaohe Experimental Forest (between $43^{\circ} 58^{\prime}-44^{\circ} 05^{\prime} \mathrm{N}$ and $127^{\circ} 44.1^{\prime}-127^{\circ} 44.7^{\prime} \mathrm{E}$ ) in Jilin Province, in northeastern China, at an average elevation of $450 \mathrm{~m}$. The area has a continental monsoon climate with a mean annual temperate of $3.8{ }^{\circ} \mathrm{C}$ and mean annual precipitation of $695.9 \mathrm{~mm}$ concentrated in the summer (June-August)[31,40]. The soil is mainly a dark brown forest soil. The study area is covered by a natural stands of secondary coniferous and broadleaved mixed forest consists of Pinus koraiensis, Quercus mongolica, Tilia amurensis, Fraxinus mandshurica, Juglans mandshurica, Acer mandshuricum, Acer mono, Ulmus davidiana var. japonica, Betula platyphylla and other trees. The understory vegetation is a rich mixture of species, with a shrub layer dominated by Syringa reticulata var. amurensis, Acer barbinerve, Corylus mandshurica, Eleutherococcus senticosus, Philadelphus. schrenkii, Sorbaria sorbifolia, Ribes spp. and other species, while the herb layer is dominated by Aegopodium alpestre, Adiantum spp., Cardamine leucantha, Meehania fargesii, Pteridophyta, Carex spp., Brachybotrys paridiformis and Hylomecon japonica.

\subsection{Species selection}

We surveyed understory species based on fixed plots (total area of plots: $130 \mathrm{ha}$ ) that were established in 2009-2010 by Zhao and his team [41-43] from which we selected twenty shrub species and four tree species representing eleven families as our research objects (Table 2). The twenty shrub species were divided, by morphology characteristics, to tree-like shrubs that have a single-stem and apparent trunk [10], and typical shrubs that are multi-stemmed, low-branching and not obvious in trunk [14]. Four tree species were small individual trees and defined as saplings. The names and types of sampled species are shown in Table 2. These are all broadleaved-deciduous and widely distributed in natural secondary coniferous and broadleaved mixed forests in northeastern China.

\subsection{Species sampling}

The number of plants selected for each species varied between 11 and 51 to cover ranges of their sizes in order to cover the widest possible range of plant sizes according to the data from our field plots. The species sampled were selected from the same forest style and we tried to keep the climatic and soil conditions as constant as possible[17]. The selected sample plants were measured and harvested in mid-August 2013 during the peak season of increasing biomass, when foliage biomass and canopy cover were relatively stable[11].

Measurements of several morphological variables, usually used to develop equations for estimating shrub biomass, were obtained from every individual plant sampled before harvesting: basal diameter (D: stem diameter at $5 \mathrm{~cm}$ above ground, $\mathrm{cm})$; total height $(\mathrm{H}$ : 
distance from the ground to the highest crown point, $\mathrm{cm}$ ); maximum crown diameter ( $\mathrm{CD}_{1}$, $\mathrm{cm})$ and its perpendicular diameter $\left(\mathrm{CD}_{2} \mathrm{~cm}\right)$ as well as the number of ramifications (NR) from the root collar for clustered shrub species. Assuming an elliptical crown shape, crown area $\left(\mathrm{CA}, \mathrm{m}^{2}\right)$ was calculated by crown diameters $\left(\mathrm{CD}_{1}\right.$ and $\left.\mathrm{CD}_{2}\right)$ as follows:

$$
C A=\pi \times\left(C D_{1} / 2\right) \times\left(C D_{2} / 2\right) / 10000
$$

where, $\mathrm{CD}_{1}$ is the maximum crown diameter $(\mathrm{cm})$ and $\mathrm{CD}_{2}$ its perpendicular diameter (cm); 10000 is the constant for transforming the units from $\mathrm{cm}^{2}$ to $\mathrm{m}^{2}$.

The individually sampled plants were cut down at ground level and the entire root system excavated, although at times, the fine roots could not be obtained in full. All plants were divided into stem, new-branches, older-branches, foliage and roots and their fresh weight $(\mathrm{W}, \mathrm{g})$ obtained in the field using a hanging scale (YP 30000, accuracy= $1 \mathrm{~g}$ when samples more than $100 \mathrm{~g}$ or JT3101N, accuracy $=0.1 \mathrm{~g}$ when samples less than $100 \mathrm{~g}$ ). Subsamples of not less than $100 \mathrm{~g}$ of fresh weight from all components were selected from each sampling unit. When the dry mass amounted to less than $100 \mathrm{~g}$, the entire component was used as the subsample. Then, all fresh component subsamples were weighed (using JT3101N, accuracy $=0.1 \mathrm{~g}$ ), stored in envelop bags and brought to the laboratory, where the dry weight of each component subsample was obtained using an air-forced oven at $80^{\circ} \mathrm{C}$ for 48 hours or more until reaching constant weight[11]. For each species, the water content was calculated using the dry mass/ fresh mass for each component. Then the water content of each component per species multiplied by the fresh mass of the component weighed in the field obtained the dry weight [30] of foliage $\left(\mathrm{W}_{\mathrm{F}}\right)$, new-branches $\left(\mathrm{W}_{\mathrm{NB}}\right)$, old-branches $\left(\mathrm{W}_{\mathrm{OB}}\right)$, stems $\left(\mathrm{W}_{\mathrm{s}}\right)$ and roots $\left(\mathrm{W}_{\mathrm{R}}\right)$ of each species. We then obtained the biomass of the following components: branch dry weight $\left(\mathrm{W}_{\mathrm{B}}\right)=\mathrm{W}_{\mathrm{NB}}+\mathrm{W}_{\mathrm{OB}}$; aboveground dry weight (AGB) $=\mathrm{W}_{\mathrm{F}}+\mathrm{W}_{\mathrm{B}}+\mathrm{W}_{\mathrm{s}}$; total dry biomass $(\mathrm{TB})=\mathrm{AGB}+$ the belowground dry biomass $(\mathrm{BGB}=$ root biomass. We considered the entire root biomass as the belowground dry biomass.

\subsection{Data analysis}

First, species-specific allometric equations were constructed between morphological variables and dry biomass components (aboveground biomass, belowground biomass and total biomass). Second, allometric equations were developed by species groups of saplings, tree-like shrubs and typical shrubs. Seventeen equations in four model styles were chosen to fit the models using D, H and CA as the variables for aboveground biomass, underground biomass and total biomass for all twenty-four species (Table 1). Equations 7-9 and 14-17 in Table 1 are transformations from the following power function:

$$
y=a x_{1}^{b} x_{2}^{c} x_{3}^{d}
$$

where, $\mathrm{y}$ is the component biomass, $\mathrm{x} 1, \mathrm{x} 2$ and $\mathrm{x} 3$ are the morphological variables of $\mathrm{D}$, $\mathrm{H}$ and $\mathrm{CA}$; and $\mathrm{a}, \mathrm{b}, \mathrm{c}$ and $\mathrm{d}$ are constants to be calculated.

Table 1 Models for development of biomass allometric equations.

\begin{tabular}{llllll}
\hline Code & Model style & Equation & Code & Model style & Equation \\
\hline Eq.1 & Linear & $\mathrm{y}=\mathrm{a}+\mathrm{b}_{1 \mathrm{x} 1}$ & Eq.10 & Multiple linear & $\mathrm{y}=\mathrm{a}+\mathrm{bx}_{1}+\mathrm{cx}_{2}$
\end{tabular}




\begin{tabular}{|c|c|c|c|c|c|}
\hline Eq.2 & Linear & $y=a+b x_{2}$ & Eq.11 & Multiple linear & $y=a+b x_{2}+c x_{3}$ \\
\hline Eq.3 & Linear & $y=a+b x_{3}$ & Eq.12 & Multiple linear & $y=a+b x_{1}+c x_{3}$ \\
\hline Eq.4 & Quadratic & $y=a+b x_{1}+c x_{1}$ & Eq.13 & Multiple linear & $y=a+b x_{1}+c x_{2}+d x_{3}$ \\
\hline Eq.5 & Quadratic & $y=a+b x_{2}+c x_{2}$ & Eq.14 & Logarithmic & $\ln y=\ln a+b \ln x_{1}+c \ln x_{2}$ \\
\hline Eq.6 & Quadratic & $y=a+b x_{3}+c x_{3}$ & Eq.15 & Logarithmic & $\ln y=\ln a+b \ln x_{2}+c \ln x_{3}$ \\
\hline Eq.7 & Logarithmic & $\ln y=\ln a+b \ln x_{1}$ & Eq.16 & Logarithmic & $\ln y=\ln a+b \ln x_{1}+c \ln x_{3}$ \\
\hline Eq.8 & Logarithmic & $\ln y=\ln a+b \ln x_{2}$ & Eq.17 & Logarithmic & $\ln y=\ln a+b \ln x_{1}+c \ln x_{2}+d \ln x_{3}$ \\
\hline Eq.9 & Logarithmic & $\ln y=\ln a+b \ln x_{3}$ & & & \\
\hline
\end{tabular}

$\mathrm{y}$ is the components biomass including aboveground biomass (AGB, g), belowground biomass (BGB, g) and total biomass (TB, g); $x_{1}, x_{2}$ and $x_{3}$ are independent variables, i.e., basal diameter $(\mathrm{D}, \mathrm{cm})$, total height $(\mathrm{H}, \mathrm{cm})$ and crown area $\left(\mathrm{CA}, \mathrm{m}^{2}\right)$, respectively; $\mathrm{a}, \mathrm{b}, \mathrm{c}$ and $\mathrm{d}$ are constants to be calculated.

Given that logarithmic transformations introduce a systematic bias[44] and tends to underestimate[17]. Thus, a correction factor (CF) should be introduced in order to account for the inherent bias caused by the log transformation. The final back-transformed model was of the form:

$$
y=C F \times a x_{1}^{b} x_{2}^{c} x_{3}^{d}
$$

where,

$$
C F=e^{\left(S E E^{2} / 2\right)}
$$

$\mathrm{CF}$ is the correction factor and SEE the standard error of the estimate; other variables have the same meaning as in equation (2).

The best models developed for species-specific or multispecies were selected on the basis of their Akaike Information Criterion (AIC) [45,46] which describes the trade-off between bias and variance in model construction. Simultaneously, the coefficient of determination $\left(R^{2}\right)$, the fit index (FI), the standard error of the estimate (SEE) and the F value were used to evaluate the goodness of fit models.

These functions are defined as:

$$
\begin{gathered}
A I C=2 k+n \ln \left(\frac{1}{n} \sum_{i=1}^{n}\left(y_{i}-\hat{y}_{i}\right)^{2}\right) \\
F I\left(R^{2}\right)=1-\sum_{i=1}^{n}\left(y_{i}-\hat{y}_{i}\right)^{2} / \sum_{i=1}^{n}\left(y_{i}-\bar{y}\right)^{2} \\
F=\frac{\left(\sum_{i=1}^{n}\left(y_{i}-\bar{y}\right)^{2}-\sum_{i=1}^{n}\left(y_{i}-\hat{y}_{i}\right)^{2}\right) / k}{\sum_{i=1}^{n}\left(y_{i}-\bar{y}\right)^{2} /(n-k-1)}
\end{gathered}
$$

where, $\mathrm{k}$ is the number of parameters, $\mathrm{n}$ the number of sampled individuals, $\mathrm{y}_{\mathrm{i}}$ the observed value, $\hat{y}_{i}$ the estimated value of the component biomass of sampling individual $\mathrm{i}$ 
and $\bar{y}$ the observed mean value of biomass.

FI is similar to the coefficient of determination $\left(R^{2}\right)$ in linear regression models[47]. However, it is necessary to calculate FI because the $\mathrm{R}^{2}$ may not be directly comparable among log-transformed and untransformed independent variables.

We only developed models about TB, AGB and BGB as functions of $\mathrm{D}, \mathrm{H}$ and CA for all species, while the other component biomass models such as $\mathrm{W}_{\mathrm{F}}, \mathrm{W}_{\mathrm{NB}}, \mathrm{W}_{\mathrm{OB}}, \mathrm{W}_{\mathrm{s}}$ and $\mathrm{W}_{\mathrm{R}}$ are expected to be presented in subsequent studies.

All analyses were executed with R software (version 3.2.3; R Development Core Team 2014) using the $n l s$ package for model construction. The graphs were drawn using Sigmaplot 10.0 (Systat Software, Inc 2006).

\section{Results}

Among the twenty four species of the understory, four belong to sapling style species (total 117 individual plants), nine are tree-like shrubs (total 305 individual plants) and eleven are typical shrubs (a total of 206 individual plants or a total of 446 plants including ramifications). For the sapling species, the largest $\mathrm{D}, \mathrm{H}$ and $\mathrm{CA}$ appeared in Acer mono, with their corresponding AGB and TB showing the highest values, although the largest BGB value was found in Acer mandshuricum. Similarly, Syringa reticulata var. amurensis exhibited the largest D, H and CA among tree-like shrubs as well as the BGB, AGB and TB. Among the typical shrubs investigated, Acer barbinerve showed the largest values of $\mathrm{BGB}, \mathrm{AGB}$ and $\mathrm{TB}$ per plant in correspondence with their $\mathrm{D}, \mathrm{H}$ and $\mathrm{CA}$, which were much greater than for other species. However, the number of ramifications of Ribes mandshuricum and Viburnum burejaeticum per plant were maximum (both 11) of all shrub-like species. Names, family, number of sampled species, the number of ramifications (only for typical shrubs), the range of values of biometric variables (D, $\mathrm{H}$ and $\mathrm{CA}$ ) as well as the component biomass (BGB, AGB and TB) per species are shown in Table 2.

Table.2 Range of sizes and biomass components by individual species.

\begin{tabular}{|c|c|c|c|c|c|c|c|c|c|c|}
\hline Species & Family & tyle & $\mathbf{N}$ & NR & $D(\mathrm{~cm})$ & $\mathrm{H}(\mathrm{cm})$ & $\mathrm{CA}\left(\mathrm{m}^{2}\right)$ & BGB(g) & $\operatorname{AGB}(g)$ & $\mathrm{TB}(\mathrm{g})$ \\
\hline $\begin{array}{l}\text { Acer } \\
\text { mandshuricum }\end{array}$ & cor & pling & 30 & - & $.497-7.100$ & -650 & 0.039-7.304 & $1.3-1737.5$ & 4.6-5101.4 & $6.0-6$ \\
\hline Acer mono & Aceraceae & $\lg$ & 3 & - & 1 & 50 & 64 & & .1 & 3 \\
\hline Carpin & Betul & $\operatorname{gg}$ & 28 & - & $0.45-2-3-2$ & 30 & 0.0 & & & 8.1 \\
\hline Ulmus & m & ling & 27 & - & 0.25 & 585 & 0.118 & 1.3 & 62.2 & $2.6-5078.7$ \\
\hline $\begin{array}{l}\text { Corylus } \\
\text { mandshurica }\end{array}$ & Corylaceae & & 36 & - & & & 98 & 3.0 & 6.2 & 2 \\
\hline $\begin{array}{l}\text { Eleutherococc } \\
\text { senticosus }\end{array}$ & raliaceae & ke & 26 & - & 0.2 & 20 & 40 & .1 & & 5 \\
\hline Euon & e & ke & 21 & - & 5 & 30 & 0. & 2. & .6 & 9.6 \\
\hline $\begin{array}{l}\text { Euonym } \\
\text { verrucos }\end{array}$ & Cela & e-like & 51 & - & 39 & -505 & 0.008 & 40.1 & 33.4 & $2.0-3973.5$ \\
\hline Prunus padus & e & -like & 39 & - & 83 & 05 & 0.0 & 5.0 & 20.1 & $26.1-6772.9$ \\
\hline $\begin{array}{l}\text { Rhamnus } \\
\text { schneideri }\end{array}$ & Rhamnaceae & tree-like & 26 & - & 935 & $85-360$ & 0.061 & 36.7 & $19.0-3$ & 27.9-3886.1 \\
\hline Sorbaria sorbifolia & Rosaceae & tree-like & 41 & - & $0.460-1.817$ & $52-195$ & $0.047-1.649$ & $2.1-89.8$ & $0.9-142.7$ & $6.4-312.8$ \\
\hline $\begin{array}{l}\text { Syringa reticulata } \\
\text { var. amurensis }\end{array}$ & Oleaceae & tree-like & 37 & - & $0.533-7.933$ & $42-630$ & $0.001-12.456$ & $3.4-2646.7$ & $4.1-8041.0$ & $10.2-1068$ \\
\hline
\end{tabular}




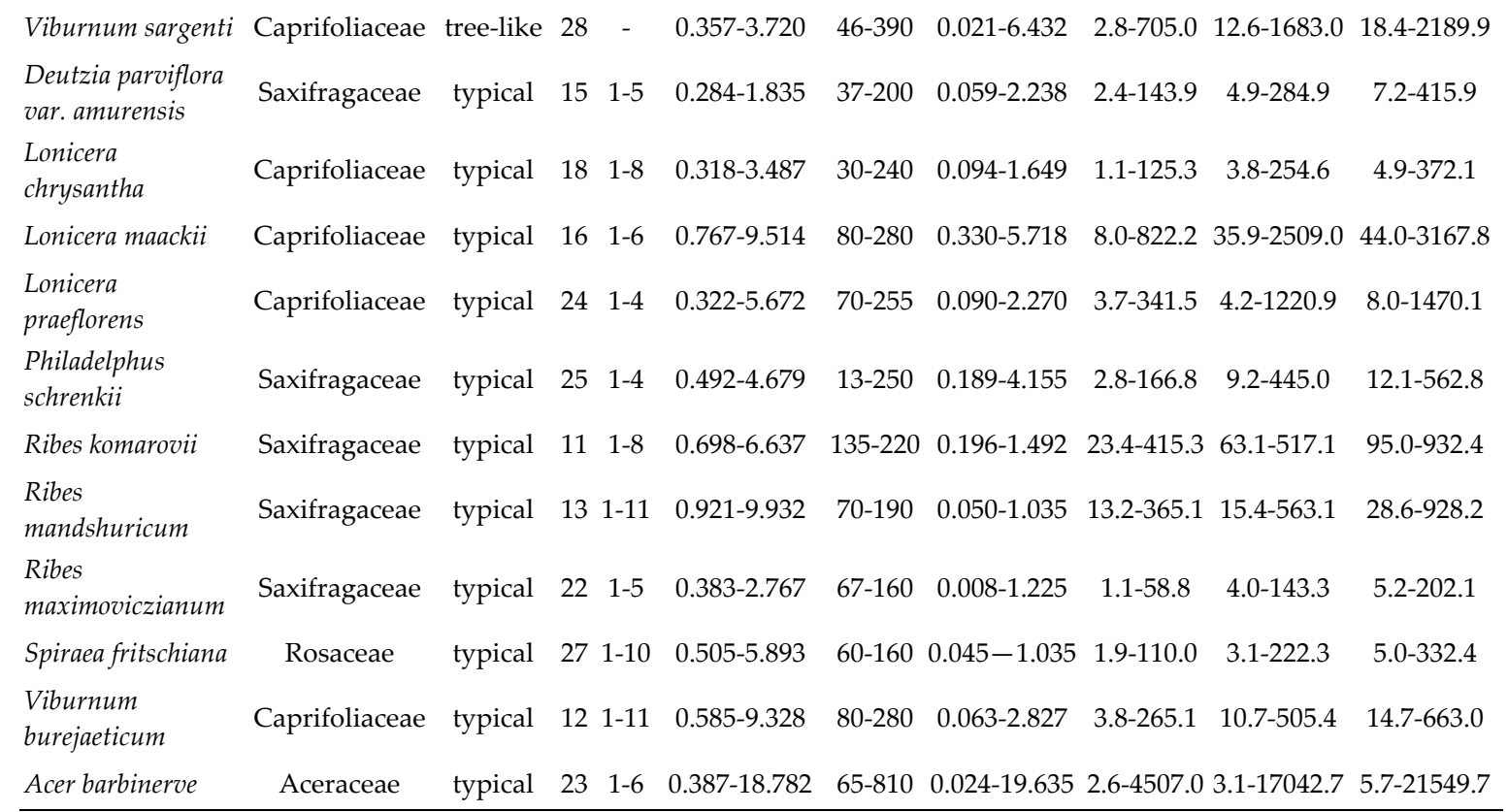

N-number of individual samples, NR-number of ramifications, D- basal diameter, H-total height, CAcrown area, BGB-belowground biomass (also root biomass), AGB-aboveground biomass, and TB- total biomass.

\subsection{Biomass models by species-specific}

The optimal equations of AGB, BGB and TB by species, their corresponding parameters, goodness of fit statistics and correction factors are shown in Table 3. Most species-specific regression models relating components biomass with measured variables were statistically highly significant $(\mathrm{p}<0.001)$. However, the optimal models styles were not the same for all species (Table 3).

Table 3. The best fit equations for AGB, BGB and TB of twenty four species.

\begin{tabular}{|c|c|c|c|c|c|c|c|c|c|c|c|c|c|}
\hline Species & Components & Equations & $\ln a$ & a or $a^{\prime 1}$ & $\mathbf{b}$ & c & d & $\mathbf{R}^{2}$ & FI & SEE & $\mathrm{CF}$ & $\mathbf{p}$ & F \\
\hline \multirow{3}{*}{$\begin{array}{c}\text { A. } \\
\text { mandshuricum }\end{array}$} & BGB & Eq.7 & 3.348 & 28.4 & 2.416 & & & 0.934 & 0.954 & 0.470 & 1.117 & $<0.001$ & 364.9 \\
\hline & AGB & Eq.7 & 4.495 & 89.6 & 2.498 & & & 0.945 & 0.916 & 0.439 & 1.101 & $<0.001$ & 447.3 \\
\hline & ТВ & Eq.7 & 4.773 & 118.2 & 2.479 & & & 0.944 & 0.928 & 0.443 & 1.103 & $<0.001$ & 434.2 \\
\hline \multirow{3}{*}{ A. mono } & BGB & Eq.4 & & 80.4 & -102.8 & 40.7 & & 0.982 & 0.982 & 61.170 & & $<0.001$ & 795.2 \\
\hline & AGB & Eq.14 & -2.990 & 0.051 & 1.498 & 1.306 & & 0.991 & 0.934 & 0.208 & 1.022 & $<0.001$ & 1653 \\
\hline & TB & Eq.7 & 3.819 & 45.6 & 2.406 & & & 0.976 & 0.953 & 0.317 & 1.051 & $<0.001$ & 1243 \\
\hline \multirow{3}{*}{ C. cordata } & BGB & Eq.7 & 2.788 & 16.3 & 2.319 & & & 0.977 & 0.969 & 0.270 & 1.037 & $<0.001$ & 1108 \\
\hline & AGB & Eq.7 & 3.492 & 33.7 & 2.712 & & & 0.988 & 0.981 & 0.230 & 1.027 & $<0.001$ & 2082 \\
\hline & ТВ & Eq.7 & 3.908 & 49.8 & 2.595 & & & 0.989 & 0.981 & 0.206 & 1.022 & $<0.001$ & 2369 \\
\hline \multirow{3}{*}{ U. laciniata } & BGB & Eq.16 & 3.050 & 21.499 & 1.554 & 0.437 & & 0.992 & 0.963 & 0.190 & 1.018 & $<0.001$ & 1416 \\
\hline & AGB & Eq.16 & 3.752 & 42.6 & 2.103 & 0.382 & & 0.997 & 0.976 & 0.132 & 1.009 & $<0.001$ & 4219 \\
\hline & TB & Eq.16 & 4.202 & 66.8 & 1.889 & 0.430 & & 0.997 & 0.974 & 0.131 & 1.009 & $<0.001$ & 3865 \\
\hline \multirow{2}{*}{ C. mandshurica } & BGB & Eq.16 & 4.115 & 61.2 & 1.202 & 0.538 & & 0.923 & 0.963 & 0.495 & 1.130 & $<0.001$ & 196.9 \\
\hline & AGB & Eq.7 & 3.617 & 37.2 & 2.669 & & & 0.985 & 0.983 & 0.246 & 1.031 & $<0.001$ & 2290 \\
\hline
\end{tabular}




\begin{tabular}{|c|c|c|c|c|c|c|c|c|c|c|c|}
\hline & ТВ & Eq.15 & -2.163 & 0.110 & 1.467 & 0.640 & 0.9810 .984 & 0.267 & 1.036 & $<0.001$ & 832.9 \\
\hline & BGB & Eq.7 & 2.687 & 14.7 & 1.919 & & $0.848 \quad 0.626$ & 0.398 & 1.082 & $<0.001$ & 133.9 \\
\hline \multirow[t]{3}{*}{ E. enticosus } & AGB & Eq. 8 & -5.771 & 0.003 & 1.874 & & 0.8890 .773 & 0.372 & 1.072 & $<0.001$ & 192.9 \\
\hline & $\mathrm{TB}$ & Eq.7 & 3.720 & 41.3 & 2.067 & & $\begin{array}{lll}0.880 & 0.731\end{array}$ & 0.373 & 1.072 & $<0.001$ & 176.7 \\
\hline & BGB & Eq.7 & 2.522 & 12.5 & 2.337 & & 0.9090 .878 & 0.565 & 1.173 & $<0.001$ & 189.4 \\
\hline \multirow[t]{3}{*}{ E. alatus } & AGB & Eq.4 & & 113.5 & -260.9 & 152.7 & 0.9930 .993 & 20.5 & & $<0.001$ & 1223 \\
\hline & TB & Eq.16 & 4.089 & 59.7 & 2.124 & 0.260 & 0.9800 .981 & 0.229 & 1.027 & $<0.001$ & 437.2 \\
\hline & BGB & Eq.7 & 2.789 & 16.3 & 2.401 & & 0.9710 .992 & 0.345 & 1.061 & $<0.001$ & 2930 \\
\hline \multirow[t]{3}{*}{ E. verrucosus } & AGB & Eq.7 & 3.614 & 37.1 & 2.508 & & 0.9850 .995 & 0.257 & 1.033 & $<0.001$ & 3198 \\
\hline & $\mathrm{TB}$ & Eq.7 & 4.008 & 55.1 & 2.451 & & $\begin{array}{lll}0.988 & 0.997\end{array}$ & 0.222 & 1.025 & $<0.001$ & 4071 \\
\hline & BGB & Eq.7 & 2.859 & 17.4 & 2.815 & & 0.9610 .958 & 0.380 & 1.075 & $<0.001$ & 899.9 \\
\hline \multirow[t]{3}{*}{ P. padus } & AGB & Eq.7 & 3.904 & 49.6 & 2.471 & & 0.9810 .975 & 0.228 & 1.026 & $<0.001$ & 1916 \\
\hline & TB & Eq.7 & 4.234 & 69.0 & 2.559 & & 0.9820 .992 & 0.229 & 1.027 & $<0.001$ & 2047 \\
\hline & BGB & Eq.7 & 2.694 & 14.8 & 2.293 & & 0.9510 .846 & 0.320 & 1.052 & $<0.001$ & 469.5 \\
\hline \multirow[t]{3}{*}{ R. schneideri } & AGB & Eq.16 & 4.231 & 68.8 & 1.876 & 0.381 & $\begin{array}{lll}0.974 & 0.901\end{array}$ & 0.260 & 1.034 & $<0.001$ & 426.4 \\
\hline & TB & Eq.16 & 4.509 & 90.9 & 1.865 & 0.360 & $\begin{array}{lll}0.981 & 0.923\end{array}$ & 0.219 & 1.024 & $<0.001$ & 580.8 \\
\hline & BGB & Eq.7 & 2.884 & 17.9 & 2.435 & & 0.9710 .967 & 0.347 & 1.062 & $<0.001$ & 1155 \\
\hline \multirow[t]{3}{*}{$\begin{array}{l}\text { S. reticulata var. } \\
\text { amurensis }\end{array}$} & AGB & Eq.16 & 3.720 & 41.3 & 2.383 & 0.162 & 0.9760 .920 & 0.356 & 1.065 & $<0.001$ & 689.1 \\
\hline & TB & Eq.7 & 3.941 & 51.5 & 2.611 & & 0.9810 .935 & 0.301 & 1.046 & $<0.001$ & 1770 \\
\hline & BGB & Eq.4 & & 32.115 & -80.4 & 62.4 & 0.9360 .936 & 5.846 & & $<0.001$ & 279.5 \\
\hline \multirow[t]{3}{*}{ S. sorbifolia } & AGB & Eq.7 & 3.755 & 42.7 & 3.002 & & 0.9870 .961 & 0.128 & 1.008 & $<0.001$ & 2906 \\
\hline & TB & Eq.7 & 4.104 & 60.6 & 2.816 & & 0.9850 .986 & 0.128 & 1.008 & $<0.001$ & 2544 \\
\hline & BGB & Eq.7 & 4.114 & 61.2 & 1.949 & & 0.7010 .744 & 0.860 & 1.447 & $<0.001$ & 61.0 \\
\hline \multirow[t]{3}{*}{$\begin{array}{l}\text { Viburnum } \\
\text { sargenti }\end{array}$} & AGB & Eq.8 & -6.037 & $2.4 \mathrm{E}-03$ & 2.229 & & 0.9100 .851 & 0.391 & 1.079 & $<0.001$ & 264.3 \\
\hline & TB & Eq. 8 & -5.858 & $2.9 \mathrm{E}-03$ & 2.258 & & $0.908 \quad 0.887$ & 0.403 & 1.085 & $<0.001$ & 255.1 \\
\hline & BGB & Eq.5 & & 116.2 & -2.189 & 0.009 & 0.9930 .993 & 83.280 & & $<0.001$ & 1406 \\
\hline \multirow[t]{3}{*}{ A. barbinerve } & AGB & Eq.5 & & 948.0 & -12.475 & 0.040 & 0.9940 .994 & 288.600 & & $<0.001$ & 1633 \\
\hline & ТВ & Eq.5 & & 1064.0 & -14.660 & 0.049 & 0.9950 .995 & 331.700 & & $<0.001$ & 1986 \\
\hline & BGB & Eq. 8 & -6.798 & $1.1 \mathrm{E}-03$ & 2.188 & & 0.6920 .786 & 0.614 & 1.207 & $<0.001$ & 56.3 \\
\hline \multirow[t]{3}{*}{$\begin{array}{l}\text { D. parviflora } \\
\text { var. amurensis }\end{array}$} & AGB & Eq.16 & 4.158 & 64.0 & 1.712 & 0.296 & $\begin{array}{lll}0.958 & 0.940\end{array}$ & 0.253 & 1.033 & $<0.001$ & 271.5 \\
\hline & $\mathrm{TB}$ & Eq.11 & & -63.9 & 149.8 & 78.6 & 0.9170 .917 & 32.930 & & $<0.001$ & 132.3 \\
\hline & BGB & Eq.7 & 2.888 & 18.0 & 1.624 & & $0.903 \quad 0.821$ & 0.413 & 1.089 & $<0.001$ & 148.1 \\
\hline \multirow[t]{3}{*}{ L. chrysantha } & AGB & Eq.7 & 3.655 & 38.6 & 1.846 & & 0.9300 .625 & 0.391 & 1.080 & $<0.001$ & 213.1 \\
\hline & TB & Eq.7 & 4.055 & 57.7 & 1.767 & & 0.9370 .705 & 0.355 & 1.065 & $<0.001$ & 237.6 \\
\hline & BGB & Eq.7 & 2.885 & 17.9 & 1.598 & & 0.8240 .656 & 0.607 & 1.203 & $<0.001$ & 65.7 \\
\hline \multirow[t]{2}{*}{ L. maackii } & AGB & Eq.16 & 4.739 & 114.3 & 0.806 & 0.932 & $0.968 \quad 0.914$ & 0.247 & 1.031 & $<0.001$ & 195.6 \\
\hline & TB & Eq.16 & 4.913 & 136.0 & 0.907 & 0.842 & 0.9580 .904 & 0.287 & 1.042 & $<0.001$ & 148.2 \\
\hline L. praeflorens & BGB & Eq.16 & 3.740 & 42.1 & 0.695 & 0.909 & $\begin{array}{lll}0.852 & 0.591\end{array}$ & 0.608 & 1.203 & $<0.001$ & 60.5 \\
\hline
\end{tabular}




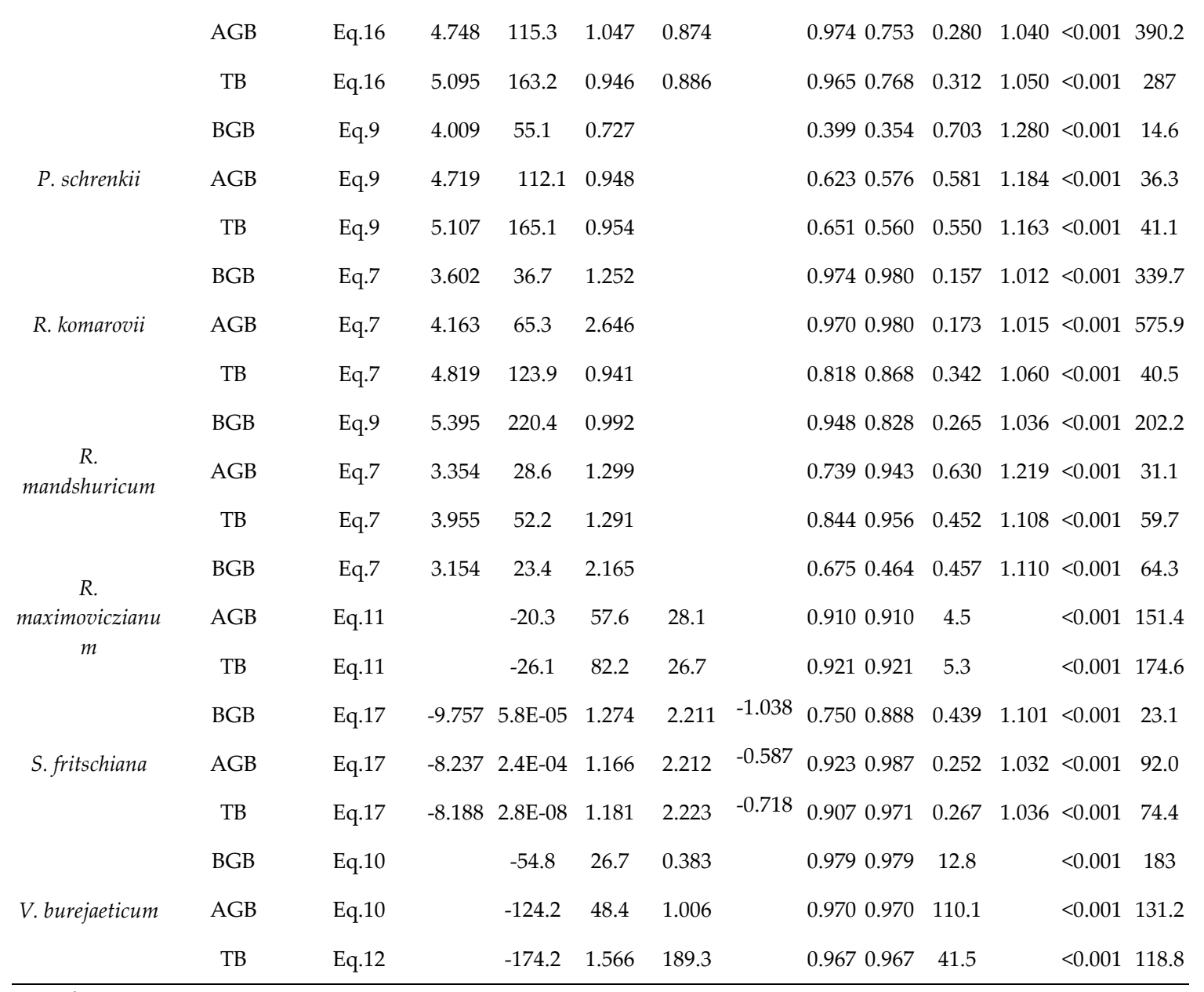

${ }^{1} \mathrm{a}^{\prime}$ is only associated with logarithmic models and calculated as a'=exp (lna). Otherwise, the a was used.

Among species-specific optimal equations for AGB, BGB and TB, the models of the style of Eq.7 were the most commonly used from all alternative equations, i.e., 32 equations among 72 equations, accounting for almost for $45 \%$ of all equations. Next in line was Eq.16, with 14 equations accounting for almost $20 \%$ of all equations. As well, equations.4-5 and 8-15 were used, with 26 accounting for slightly more than $35 \%$. It is to be noted that of these optimal models more than $75 \%$ (56 of 72) belong to a logarithmic style model. D was the best predictor variable for component biomass among species-specific equations and occurred in 58 optimal equations. CA was the second best predictor variable, used in 21 optimal 1 equations, while, $\mathrm{H}$ was the least often used. The $\mathrm{R}^{2}$ of all optimal equations varied between 0.675 for BGB in $R$. maximoviczianum and 0.997 for AGB and TB in U. laciniata. FI values, calculated based on predicted and observed values, varied from 0.464 for BGB in R. maximoviczianum to 0.996 for TB in E. verrucosus.

For most species, the $\mathrm{R}^{2}$ values of the best fitted models for AGB and TB exceeded 0.9; the exceptions were E. enticosus, P. schrenkii, R. komarovii and R. mandshuricum). The lowest $\mathrm{R}^{2}$ value scored was for AGB in $R$. mandshuricum $\left(\mathrm{R}^{2}=0.739\right)$. $\mathrm{R}^{2}$ values of $B G B$, which ranged between 0.675 (R. maximoviczianum) and 0.992 (U. laciniata), were relatively smaller than those of AGB and TB in most species with the exception of R. komarovii, $R$. mandshuricum and $V$. burejaeticum (Table 3). 


\subsection{Biomass equations by multispecies for three groups}

As single independent variables $\mathrm{D}, \mathrm{H}$ and $\mathrm{CA}$ were all highly significant for AGB, BGB and $\mathrm{TB}$ for three multispecies groups of saplings, tree-like shrubs and typical shrubs $(\mathrm{p}<0.001)$. However, the explanatory capabilities of these three variables varied for different components and groups (Fig.1). Among the three groups models of multispecies considered, the sapling multispecies (Fig. 1a, b and c) and tree-like shrub multispecies (Fig.1d, e and f) had higher explanatory capabilities than the typical shrubs (Fig. 1g, h and i) for the three independent variables, with the sapling multispecies slightly higher than for the tree-like shrub multispecies. For the biomass components of each group multispecies, the explanatory capabilities for AGB and TB of three variables were similar and higher than for BGB. Of the three independent variables involved, D had usually the highest explanatory capabilities for all components and groups of multispecies, followed by the $\mathrm{H}$ and the lowest in CA (Fig. 1).
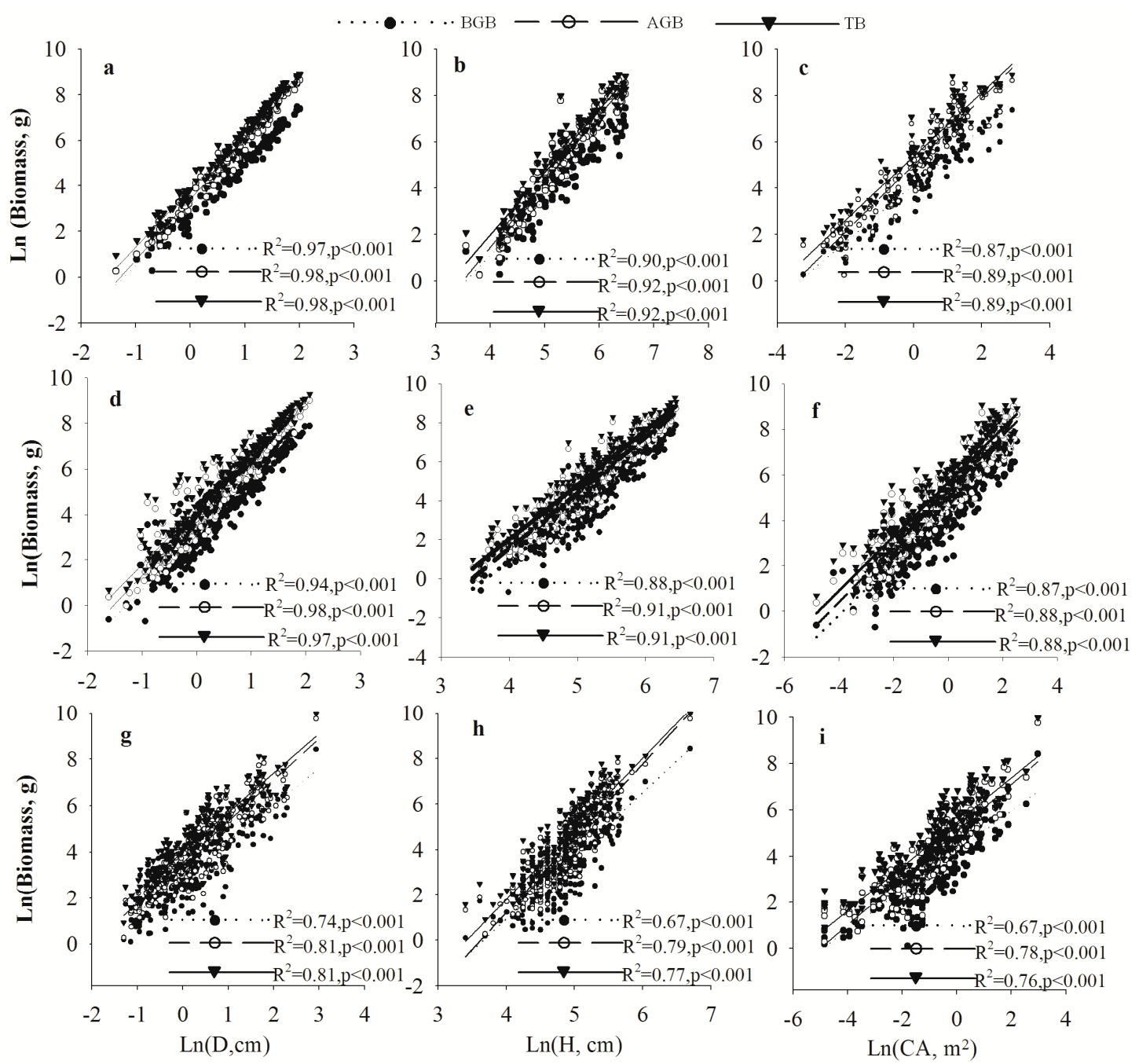

Figure 1. Belowground biomass (BGB, g), aboveground biomass (AGB, g) and total biomass (TB, g) as functions of basal diameter $\mathrm{D}(\mathrm{cm})$, total height $\mathrm{H}(\mathrm{cm})$ or crown area $\mathrm{CA}\left(\mathrm{m}^{2}\right)$ of saplings $(\mathrm{a}, \mathrm{b}$ and $\mathrm{c})$, tree-like shrubs (d, e and f) and typical shrubs ( $\mathrm{g}$, $\mathrm{h}$ and i) in the understory. The total number of sampled plants was the same for three biomass components, 117 for saplings, 305 for tree-like shrubs, and 206 for typical shrubs. The various symbols and colors represent different biomass components, a black solid circle represents for BGB, a white hollow circle for AGB and a black inverted triangle for TB. 
Goodness fit ( $\mathrm{R}^{2}$ and p-value) of the regression models are provided for BGB (dotted line), AGB (medium dash line) and TB (solid line) for the three single independent variables, i.e., D, H and CA.

We developed multispecies regression models of BGB, AGB and TB for three different groups of understory species, i.e., saplings, tree-like shrubs and typical shrub and selected the best fitting multispecies models based on AIC and RMSE for BGB, AGB and TB of the three groups of multispecies, with their goodness fit and statistical descriptors shown in Table 4. These models are all of a logarithmic form, using multiple-variables, except for the multispecies model of BGB for saplings. Similarly as in the best fitting species-specific models, $\mathrm{D}$ was the most commonly used variable for all optimum multispecies models (all models used this variable) (Table 4). These optimum models displayed high explanatory capability $\left(\right.$ all $\mathrm{R}^{2}>0.8$ ) with $\mathrm{p}$ values $<0.001$. Although the best-fit typical shrub models had more plant size variables (all three variables) than sapling or tree-like shrub models, their explanatory capabilities were lower. Biomass variability among individual plants was greater in typical shrubs than in saplings and tree-like shrubs.

Table 4. The best fit equations for biomass components of AGB, BGB and TB by three species groups of understory plants.

\begin{tabular}{|c|c|c|c|c|c|c|c|c|}
\hline Species group & Component & Best fit model & $\mathbf{R}^{2}$ & FI & SEE & $\mathrm{CF}$ & p & $\mathbf{F}$ \\
\hline \multirow{3}{*}{ Sapling } & BGB & $\ln B G B=2.752+2.2591 n D$ & 0.969 & 0.948 & 0.322 & 1.053 & $<0.001$ & 3390 \\
\hline & AGB & $\ln \mathrm{AGB}=3.626+2.258 \ln \mathrm{D}+0.242 \ln \mathrm{CA}$ & 0.986 & 0.914 & 0.253 & 1.033 & $<0.001$ & 3787 \\
\hline & TB & $\ln \mathrm{TB}=1.610+2.1221 \ln \mathrm{D}+0.470 \ln \mathrm{H}$ & 0.985 & 0.956 & 0.251 & 1.032 & $<0.001$ & 3508 \\
\hline \multirow{3}{*}{$\begin{array}{c}\text { Tree-like } \\
\text { shrub }\end{array}$} & BGB & $\ln B G B=-2.347+1.458 \ln \mathrm{D}+1.121 \ln H$ & 0.914 & 0.933 & 0.574 & 1.179 & $<0.001$ & 1599 \\
\hline & AGB & $\ln \mathrm{AGB}=-1.952+1.532 \ln \mathrm{D}+1.194 \ln \mathrm{H}$ & 0.938 & 0.931 & 0.507 & 1.137 & $<0.001$ & 2292 \\
\hline & $\mathrm{TB}$ & $\operatorname{lnTB}=-1.437+1.489 \ln \mathrm{D}+1.175 \ln \mathrm{H}$ & 0.942 & 0.951 & 0.479 & 1.121 & $<0.001$ & 2451 \\
\hline \multirow{3}{*}{ Typical shrub } & BGB & $\ln B G B=-1.549+0.8361 \ln D+1.004 \ln H+0.23 \ln C A$ & 0.812 & 0.938 & 0.676 & 1.257 & $<0.001$ & 472.5 \\
\hline & AGB & $\ln \mathrm{AGB}=-2.240+0.787 \ln \mathrm{D}+1.312 \ln \mathrm{H}+0.33 \ln \mathrm{CA}$ & 0.925 & 0.970 & 0.463 & 1.113 & $<0.001$ & 916.2 \\
\hline & TB & $\operatorname{lnTB}=-1.524+0.778 \ln \mathrm{D}+1.249 \ln \mathrm{H}+0.3 \ln \mathrm{CA}$ & 0.910 & 0.978 & 0.485 & 1.125 & $<0.001$ & 752.5 \\
\hline
\end{tabular}

The comparison between observed and predicted values (calculated from the optimum models and shown in Table 3) of AGB, BGB and TB for the three species groups of multispecies are displayed in Figure 2. As close as possible, the slopes of our linear regression models were approximately 1, implying that the predicted and observed values were very similar. The slopes of all regression models ranged between 0.9594 and 1.0080. Among the three species groups, the models for saplings and typical shrubs were better than those for tree-like shrubs in terms of slopes and error bias of regression model between observed and predicted values. For sapling multispecies models, the slopes of BGB, AGB and TB were $0.9999,1.0003$ and 1.0028 , respectively, indeed very close to 1 . Next were the typical shrub multispecies models, with slopes for BGB, AGB and TB of 1.0075, 1.0080 and 0.9990. Then, the slopes of tree-like shrubs multispecies models were 0.9695 for BGB, 0.9601 for AGB and 0.9594 for TB, respectively (Fig. 2). 

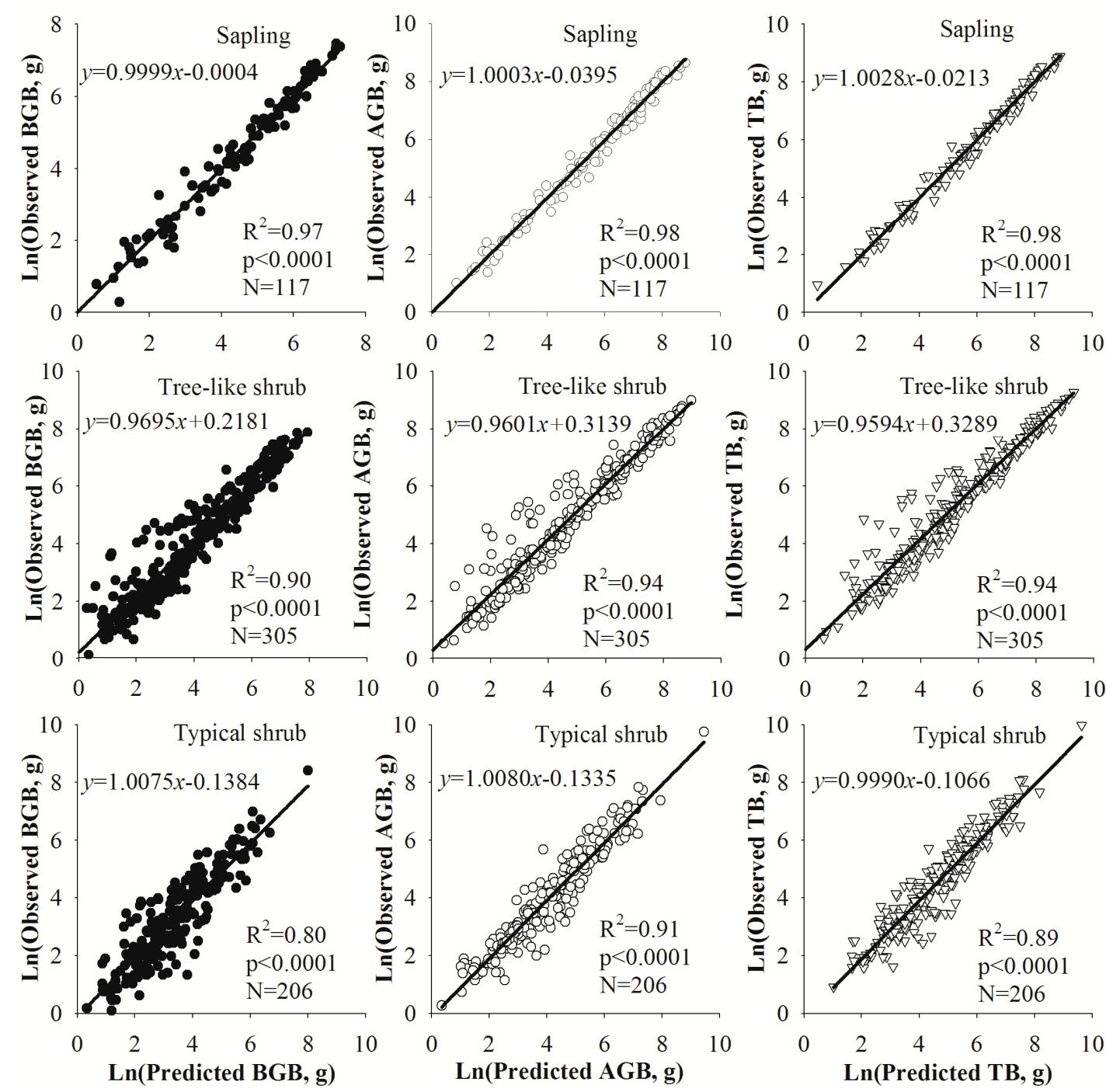

Figure 2. Ability of the best fit models to predict BGB, AGB and TB for species groups of saplings, tree-like shrubs and typical shrubs. Solid circles denote the BGB of the natural logarithmic transformation of three groups for multispecies; hollow circles represent for AGB and the hollow inverted triangles for TB. The black lines are simple regression models showing predicted values as functions of the observed values in a natural logarithm transformation. The coefficients of determination $\left(R^{2}\right)$, p-values and the number of samples for each regression equation are shown in each sub-figure.

\section{Discussion}

The model forms and prediction variables for developing biomass equations were derived from various investigations $[6,17,34,39,47,48]$. In our study, we choose three variables (basal diameter, total height and crown area) and four models (linear, quadratic, multiple and logarithmic regression) to develop species-specific and multispecies equations for BGB, AGB and TB. . The independent variables $\mathrm{D}, \mathrm{H}$ and $\mathrm{CA}$ have often been used to develop regression models for estimating biomass for shrub and sapling species $[17,32,33,48]$. In our study, the result showed that each of the three independent variables $\mathrm{D}, \mathrm{H}$ and CA have a high explanatory ability for assessing AGB, BGB and TB in all species, entirely in agreement with similar variable-biomass relationships found for understory species in other studies $[14,27,32]$. 
Stem basal diameter may be the best predictor variable to develop optimum biomass models for various understory species, specially for saplings or tree-like shrubs species, as shown in Tables 3 and 4. Occasionally crown area had to be considered for shrub-like species, specially for low-growth shrubs with multiple stem growth form, where it is difficult to measure each stem basal diameter individually[10,24,49]. Halpern et al. [49] found that basal diameter had the weakest prediction capability and the highest errors when used as the independent variable to estimate the biomass of small multiple-stem shrubs. In the semi-arid Chaco forest, Conti et al. [17] used crown area as well as crown-shaped variables to develop their species-specific and multispecies shrub models which proved to be the best, but suggested that the use of such models should be combined with total height and crown area (crown volume, $\mathrm{CV}=\mathrm{H} \times \mathrm{CA}$ ) as a single variable to predict aboveground dry biomass of shrub species. In this study, we also found that crown area was usually found in combination with height or basal diameter for optimum typical shrub species-specific models, but hardly ever used alone. The addition of height or basal diameter in models developed for shrub-like species was suitable because crown area mainly explained variation associated with horizontal growth, but not associated with any variation [10,49].

Other studies have shown that crown volume $(\mathrm{CV})$ and $\mathrm{D}^{2} \mathrm{H}$ maybe the suitable variables in addition to basal diameter, height and crown area [14,17,23,24,27,47,50]. For example, Paton et al. [23] developed log-log regression models for 22 shrub species in Monfragüe Natural Park in southwestern Spain, in which 12 species were fitted with CV as the independent variable in all optimum models. Fan et al. [27] studied fourteen saplings in the Changbai Mountain region of northeastern China, showing that an entire plant biomass can be modeled accurately with power models based on basal diameter or the product of the square of basal diameter and total height. Liu et al. [24] developed four allometric biomass equations for alpine shrub species in the Heihe River Basin of northwestern China and also showed that the optimum models of Salix cupularis and Caragana jubata were constructed, again using the product of the square of basal diameter and height. In our study, crown volume and the product of the square of basal diameter and height were not used for modeling, but may be applicable for some other species in any future studies. However, these variables may not be preferred when a single variable model can estimate biomass well enough given a combination of two variables that are difficult to measure in practice [17]. It may be an interesting investigation to develop biomass models with $\mathrm{CV}$ or $\mathrm{D}^{2} \mathrm{H}$ as independent variables for those species were two or more than two variables are called for.

In most cases, multiple-variable models are shown to have better explanatory ability than single-variable models (see Tables S1, S2 and S3). However, the more variables included in models, the more difficult and laborious the effort would be to deal with in practice. This seems to imply that more attention should be paid to the range of each variable, that more field measurements should be made and that more deviation might be expected. Models with fewer variables are more convenient and preferred and therefore, we suggest that one should opt for models with few variables when adding a variable that does not improve goodness of fit significantly. So, the selection of best biomass models should be based on not only over-all model fitting, but also applicability of models. Appropriate models can be selected from Tables S1, S2 and S3 based on the purpose for which it is needed.

The results from our optimum models developed for AGB, BGB and TB for the twenty 
four understory species show that power models, transformed by natural logarithms, were more often employed than other models for both species-specific plant communities and multispecies communities (Tables 3 and 4). The goodness of fit of the logarithmic models in these species should be no questioned, given that the validity of these models has been further confirmed in a number of other studies for various of woody plant species around the world $[17,25,31,32,40,51,52]$.

In general, species-specific models show greater accuracy in estimating biomass components than multispecies models for a given individual species, especially for root biomass (BGB) as shown in our study and for foliage and branches (not shown), as confirmed in a few studies $[10,14,53]$. However, for a particular species for which no specific regression model has been developed, it may be possible to select a model from a species of similar morphological characteristics or a multispecies model from an appropriate species group $[19,54]$.

Few belowground biomass equations are available for understory species $[55,56]$ because of the difficulty of measuring root biomass [57]. In our study, we explored the belowground biomass of 24 understory species in northeastern China and developed their optimum equations. Between above- and below-ground biomass, the predicting power of the belowground biomass models was inferior to that of the aboveground models. This may have been caused by the fact that some serious uncertainties were introduced in the harvesting process [21], such as the roots of other plants may have been included in the sample or a few root samples could not be collected or were lost, especially small roots. It is important to ensure that root systems are harvested completely, accurately and competently as possible in field sampling for measuring an entire biomass.

In this study, we developed biomass models of understory plants by species-specific or multispecies for coniferous and broadleaved mixed forest, northeastern China. The optimum models of both species-specific and multispecies, provided in our study, can estimate belowand above-ground and total biomass quite accurately for our study region. Given the limits in the number and ranges of variables sampled and our restricted study region, it is not clear that whether these models can be used in other forest types or other regions. We will verify the applicability of these models and supplement more data for other forest types and other regions in any future investigations. Our work helps the estimation of forest ecosystem carbon stocks, especially for belowground component, and provides tools for quantification of individual species biomass of understory plants. Due to various research purposes or the limitations in measuring variables, our optimum models (shown in Tables 3 or 4) are not always and everywhere appropriate to use. We provide some alternative models in our supporting documents in Tables S1, S2 and S3. We furthermore urge that special attention should be paid to the range of each variable when these models are used. When a variable is beyond our range, we suggest that this should be taken into consideration and models revised before their use.

\section{Conclusions}

This work harvested 24 understory species including 4 saplings, 9 tree-like shrubs and 11 typical shrubs in coniferous and broadleaved forest in northeastern China and developed the best fit allometric equations of above- and below-ground biomass and total biomass by 
species-specific and multispecies. The single basal diameter, height or crown area had good explanatory power for species-specific and multispecies. The logarithmic model was most desired for both components biomass. These best fit models has been developed in this study were all estimation above-and belowground and total biomass well. These models should contribute to estimating the forest ecosystem biomass and carbon stocks or sink as well as providing tools for quantification of individual biomass for understory species.

Supplementary Materials: The following are available online at www.mdpi.com/***, Table S1: The alternative biomass equations of specie-specific and multispecies biomass equations of understory saplings, Table S2: The alternative biomass equations of specie-specific and multispecies biomass equations of understory tree-like shrubs, Table S3: The alternative biomass equations of specie-specific and multispecies biomass equations of understory typical shrubs.

Acknowledgements: This research is supported by the the Program of National Natural Science Foundation of China (31670643; 31600480). We thank Dr. Jinsong Wang (Institute of Geographic Sciences and Natural Resources Research, Chinese Academy of Science) and Dr. Ruiqiang Ni (Department of Forestry, Shandong Agricultural University) for helpful and constructive comments. We gratefully acknowledge Guichun Wang, Guowen Sun, Haitao Gao and Fengjie Wang of the Jiaohe Forestry Experimental Bureau, who provided much help in field sampling and measurements. Specially, we thanks Prof. Rongzhou Man (Applied Research and Development Branch, Ontario Ministry of Natural Resources), who revised this manuscript in English langue and content.

Author Contributions: H.H. C.Z. X.Z. and F.D. conceived and designed the experiments; H.H. S.Y. and Q.Z performed the experiments; H.H. and C.Z. analyzed the data; C.Z. and X.Z. contributed reagents/materials/analysis tools; H.H. C.Z. and F.D. wrote the paper.

Conflicts of Interest: The authors declare no conflict of interest. The founding sponsors had no role in the design of the study; in the collection, analyses, or interpretation of data; in the writing of the manuscript, and in the decision to publish the results.

\section{References}

1. Zhu, B.; Wang, X.; Fang, J.; Piao, S.; Shen, H.; Zhao, S.; Peng, C. Altitudinal changes in carbon storage of temperate forests on $\mathrm{mt}$ changbai, northeast china. Journal of plant research 2010, 123, 439-452.

2. Rapp, M.; Santa Regina, I.; Rico, M.; Gallego, H.A. Biomass, nutrient content, litterfall and nutrient return to the soil in mediterranean oak forests. Forest Ecology and Management 1999, 119, 39-49.

3. Houghton, R.A. Aboveground forest biomass and the global carbon balance. Global Change Biology 2005, 11, 945-958.

4. Houghton, R.A. Balancing the global carbon budget. Annual Review of Earth and Planetary Sciences 2007, 35, 313-347.

5. Muller-Landau, H.C. Carbon cycle: Sink in the african jungle. Nature 2009, 457, 969-970.

6. Cole, T.G.; Ewel, J.J. Allometric equations for four valuable tropical tree species. Forest Ecology and Management 2006, 229, 351-360.

7. Fang, J.; Oikawa, T.; Kato, T.; Mo, W.; Wang, Z. Biomass carbon accumulation by japan's forests from 1947 to 1995. Global Biogeochemical Cycles 2005, 19, n/a-n/a.

8. Pan, Y.; Birdsey, R.A.; Fang, J.; Houghton, R.; Kauppi, P.E.; Kurz, W.A.; Phillips, O.L.; Shvidenko, A.; Lewis, S.L.; Canadell, J.G., et al. A large and persistent carbon sink in the world's forests. Science 2011, 333, 988-993. 
9. $\quad$ Fang, J.; Chen, A.; Peng, C.; Zhao, S.; Ci, L. Changes in forest biomass carbon storage in china between 1949 and 1998. Science 2001, 292, 2320-2322.

10. Sah, J.P.; Ross, M.S.; Koptur, S.; Snyder, J.R. Estimating aboveground biomass of broadleaved woody plants in the understory of florida keys pine forests. Forest Ecology and Management 2004, 203, 319-329.

11. Liu, Z.-w.; Chen, R.-s.; Song, Y.-x.; Han, C.-t. Distribution and estimation of aboveground biomass of alpine shrubs along an altitudinal gradient in a small watershed of the qilian mountains, china. Journal of Mountain Science 2015, 12, 961-971.

12. Jiquan Chen, B.S. Spatial relationships between canopy structure and understory vegetation of an old-growth douglas-fir forest. Forest Research: Open Access 2014, 03.

13. Fortier, J.; Gagnon, D.; Truax, B.; Lambert, F. Understory plant diversity and biomass in hybrid poplar riparian buffer strips in pastures. New Forests 2011, 42, 241-265.

14. Li, X.; Guo, Q.; Wang, X.; Zheng, H. Allometry of understory tree species in a natural secondary forest in northeast china. SCIENTIA SILVAE SINICAE 2010, 46, 22-32.

15. Lasky, J.R.; Uriarte, M.; Boukili, V.K.; Erickson, D.L.; John Kress, W.; Chazdon, R.L. The relationship between tree biodiversity and biomass dynamics changes with tropical forest succession. Ecology letters 2014, 17, 1158-1167.

16. Zeng, H.-Q.; Liu, Q.-J.; Feng, Z.-W.; Ma, Z.-Q. Biomass equations for four shrub species in subtropical china. Journal of Forest Research 2009, 15, 83-90.

17. Conti, G.; Enrico, L.; Casanoves, F.; Díaz, S. Shrub biomass estimation in the semiarid chaco forest: A contribution to the quantification of an underrated carbon stock. Annals of Forest Science 2013, 70, 515-524.

18. Chave, J.; Andalo, C.; Brown, S.; Cairns, M.A.; Chambers, J.Q.; Eamus, D.; Folster, H.; Fromard, F.; Higuchi, N.; Kira, T., et al. Tree allometry and improved estimation of carbon stocks and balance in tropical forests. Oecologia 2005, 145, 87-99.

19. Brown, J.K. Estimating shrub biomass from basal stem diameters. Canadian Journal of Forest Research 1976, 6, 153-158.

20. Ter-Mikaelian, M.T.; Korzukhin, M.D. Biomass equations for sixty-five north american tree species. Forest Ecology and Management 1997, 97, 1-24.

21. Wang, C. Biomass allometric equations for 10 co-occurring tree species in chinese temperate forests. Forest Ecology and Management 2006, 222, 9-16.

22. Son, Y.; Hwang, J.W.; Kim, Z.S.; Lee, W.K.; Kim, J.S. Allometry and biomass of korean pine (pinus koraiensis) in central korea. Bioresource Technology 2001, 78, 251-255.

23. Paton, D.; Nuñez, J.; Bao, D.; Muñoz, A. Forage biomass of 22 shrub species from monfragüe natural park (sw spain) assessed by $\log -\log$ regression models. Journal of Arid Environments 2002, 52, 223-231.

24. Liu, Z.; Chen, R.; Song, Y.; Han, C.; Yang, Y. Estimation of aboveground biomass for alpine shrubs in the upper reaches of the heihe river basin, northwestern china. Environmental Earth Sciences 2014, 73, 5513-5521.

25. Chaturvedi, R.K.; Raghubanshi, A.S. Aboveground biomass estimation of small diameter woody species of tropical dry forest. New Forests 2012, 44, 509-519.

26. Yang, S.; Hou, J.h.; Zhao, X.h.; Wei, L.; Li, Y.; Yao, J.; Dai, H.-j.; He, H.-j. Biomass estimation model of shrub in broad leaved korean pine (pinus koraiensis) mixed forest in jiaohe, jilin province. Guangdong Agricultural Sciences 2013, 40, 36-41. 
27. Chun-nan, F.; Sheng-jiang, P.; Jin-ping, Z.; Bing, L.; Zhong-ling, G. Biomass estimating models of saplings for 14 species in changbaishan mountains, northeastern china. Journal of Beijing Forestry University 2013, 35, 1-9.

28. Woods, K.D.; Feiveson, A.H.; Botkin, D.B. Statistical error analysis for biomass density and leaf area index estimation. Canadian Journal of Forest Research 1991, 21, 974-989.

29. Návar, J.; Méndez, E.; Nájera, A.; Graciano, J.; Dale, V.; Parresol, B. Biomass equations for shrub species of tamaulipan thornscrub of north-eastern mexico. Journal of Arid Environments 2004, 59, 657-674.

30. Smith, W.B.; Brand, G.J. Allometric biomass equations for 98 species of herbs, shrubs, and small trees. 1983.

31. Zhang, C.; Wang, J.; Zhao, X.; Xia, F.; Gadow, K.V. Sexual dimorphism in reproductive and vegetative allometry for two dioecious rhamnus plants in north-eastern china. European Journal of Forest Research 2012, 131, 1287-1296.

32. Blujdea, V.N.B.; Pilli, R.; Dutca, I.; Ciuvat, L.; Abrudan, I.V. Allometric biomass equations for young broadleaved trees in plantations in romania. Forest Ecology and Management 2012, 264, 172-184.

33. Elzein, T.M.; Blarquez, O.; Gauthier, O.; Carcaillet, C. Allometric equations for biomass assessment of subalpine dwarf shrubs. Alpine Botany 2011, 121, 129-134.

34. Ebuy, J.; Lokombe, J.; Ponette, Q.; Sonwa, D.; Picard, N. Allometric equation for predicting aboveground biomass of three tree species. Journal of Tropical Forest Science 2011, 125-132.

35. Foroughbakhch, R.; Reyes, G.; Alvarado-Vázquez, M.A.; Hernández-Piñero, J.; Rocha-Estrada, A. Use of quantitative methods to determine leaf biomass on 15 woody shrub species in northeastern mexico. Forest Ecology and Management 2005, 216, 359-366.

36. Marziliano, P.A.; Lafortezza, R.; Medicamento, U.; Lorusso, L.; Giannico, V.; Colangelo, G.; Sanesi, G. Estimating belowground biomass and root/shoot ratio of phillyrea latifolia 1 . In the mediterranean forest landscapes. Annals of Forest Science 2015, 72, 585-593.

37. Barbosa, R.I.; Silva dos Santos, J.R.; Souza da Cunha, M.; Pimentel, T.P.; Fearnside, P.M. Root biomass, root:Shoot ratio and belowground carbon stocks in the open savannahs of roraima, brazilian amazonia. Australian Journal of Botany 2012, 60, 405.

38. Mokany, K.; Raison, R.J.; Prokushkin, A.S. Critical analysis of root : Shoot ratios in terrestrial biomes. Global Change Biology 2006, 12, 84-96.

39. Litton, C.M.; Boone Kauffman, J. Allometric models for predicting aboveground biomass in two widespread woody plants in hawaii. Biotropica 2008, 40, 313-320.

40. Zhang, X.; Zhang, C.; Zhao, X. Biomass allocation patterns and allometric relationships between components of the androdioecious acer tegmentosum. Annals of Forest Science 2016, 73, 729-739.

41. Wang, J.; Zhang, C.; Zhao, X.; von Gadow, K. Reproductive allocation of two dioecious rhamnus species in temperate forests of northeast china. iForest - Biogeosciences and Forestry 2014, 7, 25-32.

42. Zhang, C.; Zhao, X.; Gadow, K.v. Analyzing selective harvest events in three large forest observational studies in north eastern china. Forest Ecology and Management 2014, 316, 100-109.

43. Zhang, C.; Jin, W.; Gao, L.; Zhao, X. Scale dependent structuring of spatial diversity in two temperate forest communities. Forest Ecology and Management 2014, 316, 110-116. 
44. Sprugel, D.G. Correcting for bias in log-transformed allometric equations. Ecology 1983, 64, 209-210.

45. Burnham, K.P.; Anderson, D.R. Model selection and multimodel inference: A practical information-theoretic approach, 2nd edn. Springer: New York, 2002.

46. Burnham, K.P. Multimodel inference: Understanding aic and bic in model selection. Sociological Methods \& Research 2004, 33, 261-304.

47. Hosoda, K.; Iehara, T. Aboveground biomass equations for individual trees of cryptomeria japonica, chamaecyparis obtusa and larix kaempferi in japan. Journal of Forest Research 2010, 15, 299-306.

48. Singh, V.; Tewari, A.; Kushwaha, S.P.S.; Dadhwal, V.K. Formulating allometric equations for estimating biomass and carbon stock in small diameter trees. Forest Ecology and Management 2011, 261, 1945-1949.

49. Halpern, C.B.; Miller, E.A.; Geyer, M.A. Equations for predicting aboveground biomass of plant species in early successional forests of the western cascade range, oregon. Northwest Science 1996, 70, 306-320.

50. He, L.; Kang, X.; Fan, X.; Gao, Y.; Feng, Q. Estimation and analysis of understory shrub biomass in changbai mountains. Journal of Nanjing Forestry University (Natural Science Edition) 2011, 35, 45-50.

51. Cai, S.; Kang, X.; Zhang, L. Allometric models for aboveground biomass of ten tree species in northeast china. Ann for Res 2013, 56, 105-122.

52. Niklas, K.J. Modelling below- and above-ground biomass for non-woody and woody plants. Annals of botany 2005, 95, 315-321.

53. Buech, R.R.; Rugg, D.J. Biomass relations of shrub components and their generality. Forest Ecology and Management 1989, 26, 257-264.

54. Nelson, B.W.; Mesquita, R.; Pereira, J.L.G.; Garcia Aquino de Souza, S.; Teixeira Batista, G.; Bovino Couto, L. Allometric regressions for improved estimate of secondary forest biomass in the central amazon. Forest Ecology and Management 1999, 117, 149-167.

55. Xiao, C.-W.; Ceulemans, R. Allometric relationships for below- and aboveground biomass of young scots pines. Forest Ecology and Management 2004, 203, 177-186.

56. Litton, C.M.; Ryan, M.G.; Tinker, D.B.; Knight, D.H. Belowground and aboveground biomass in young postfire lodgepole pine forests of contrasting tree density. Canadian Journal of Forest Research 2003, 33, 351-363.

57. Vogt, K.A.; Vogt, D.J.; Bloomfield, J. Analysis of some direct and indirect methods for estimating root biomass and production of forests at an ecosystem level. Plant and Soil 1998, 200, 71-89.

(C) 2016 by the authors; licensee Preprints, Basel, Switzerland. This article is an open access article distributed under the terms and conditions of the Creative Commons by Attribution (CC-BY) license (http://creativecommons.org/licenses/by/4.0/). 